\author{
JURNAL EINSTEIN \\ Jurnal Hasil Penelitian Bindang Fisika \\ Available online http://jurnal.unimed.ac.id/2012/index.php/einsten \\ e-issn: $2407-747 x$, p-issn $2338-1981$
}

\title{
IDENTIFIKASI PERMUKAAN DAERAH GEOTHERMAL PLTP SARULLA UNIT I MENGGUNAKAN CITRA SATELIT DI KECAMATAN PAHAE JAE KABUPATAN TAPANULI UTARA
}

\author{
Togi Tampubolon* dan Yowlanda Panggabean
}

Jurusan Fisika, Fakultas Matematika dan Ilmu Pengetahuan Alam, Universitas Negeri Medan, Indonesia

yolandapanggabean06@gmail.com

Diterima Februari 2018; Disetujui Februari 2018; Dipublikasikan Februari 2018

\begin{abstract}
ABSTRAK
Perubahan lingkungan dapat diidentifikasi dengan memanfaatkan teknologi SIG. Penelitian ini menggunakan data citra satelit Landsat 8 OLI dengan Path 129 dan Row 058 dengan periode waktu yakni tahun 2010, 2014, 2016, 2017 dan 2018. Metode penelitian yang digunakan pada penelitian ini yakni survey lapangan untuk suhu dan teknik penginderaan jarak jauh yang bertujuan untuk menganalisis perubahan lingkungan. Survey lapangan dilakukan di Kabupaten Tapanuli Utara yang terletak dikoordinat $1^{\circ} 20^{\prime}-2^{\circ} 41^{\prime} \mathrm{LU}$ dan $98^{\circ} 05^{\prime}-99^{\circ} 16^{\prime}$ BT. Analisis perubahan lingkungan dilihat dengan adanya perubahan suhu dan vegetasi atau NDVI (Normal different Vegetation Index). Parameter NDVI memiliki nilai secara berurutan yakni 0.6, 0.4, $0.3,0.25$ dan 0.3 yang menunjukkan adanya penurunan tingkat kehijauan vegetasi. Nilai suhu secara berurutan yakni $22.42^{\circ} \mathrm{C}, 26.66^{\circ} \mathrm{C}, 22.08^{\circ} \mathrm{C}, 29.52^{\circ} \mathrm{C}$ dan $19.53^{\circ} \mathrm{Cyang}$ menunjukkan adanya peningkatan suhu. Hubungan antara NDVI dan LST berbanding terbalik, apabila nilai NDVI tinggi maka nilai LST rendah, dan sebaliknya apabila nilai NDVI rendah maka nilai LST tinggi.
\end{abstract}

Kata Kunci : Kabupaten Tapanuli Utara, PLTP Sarulla Unit I, Geothermal, Landsat 8 OLI, suhu (LST) dan NDVI.

\section{PENDAHULUAN}

Energi panas bumi (geothermal) adalah panas yang tersimpan di dalam bumi, yang bila ditransfer ke permukaan bisa digunakan oleh manusia (Marzolf, 2014; Dickson, 2013). Mengingat bahwa energi panas bumi adalah sumber daya terbarukan, dapat dianggap sebagai solusi untuk masalah kekurangan lingkungan dan energi yang dihadapi dunia saat ini sehingga perlu dilakukan pengembangan energy panas bumi tersebut (Muñoz et al., 2014).

Kementrian energi dan sumber daya mineral (ESDM) memproyeksikan bahwa indonesia akan menjadi penghasil energi listrik dari tenaga panas bumi "Geothermal" terbesar di dunia dan mengalahkan produsen tenaga listrik Amerika Serikat dan Filifina di tahun 2021. PLTP PT. Sarulla ini sebenarnya dibagi menjadi tiga unit yang dikembangkan di dua lokasi. Pertama, unit I yaitu proyek Silangkitang (SIL) berkapasitas Kedua, unit II dan III yaitu proyek Namora - I - Langit (NIL) dengan besar kapasitas besar unitnya adalah $110 \mathrm{MW}$.

Dalam melakukan eksplorasi panas bumi terutama untuk menentukan perubahan vegetasi dan suhu lingkungan dapat dilakukan dengan 
memanfaatkan ilmu Geofisika. Geofisika adalah ilmu yang mempelajari tentang bumi dengan menggunakan parameter-parameter fisika. Untuk mendapatkan beberapa parameter fisika salah satunya adalah metode pengindraan jarak jauh.

Penginderaan Jauh adalah ilmu dan seni untuk memperoleh informasi tentang suatu obyek, daerah atau fenomena melalui analisis data yang diperoleh dengan suatu alat tanpa kontak langsung dengan obyek, atau fenomena yang dikaji (Lillesand, et.al., 1979).

Teknologi penginderaan jarak jauh dalam bidang eksplorasi energy panas bumi dapat digunakan untuk mengidentifikasi keadaan vegetasi dan tingkat temperature daerah penelitian. Indeks vegetasi (NDVI) adalah besaran nilai kehijauan vegetasi yang diperoleh dari pengolahan sinyal digital data nilai kecerahan (brightnes) beberapa kanal sensor satelit (Huete et al 2002).

Temperature permukaan tanah atau Land Surface Temperature (LST) merupakan keadaan yang dikendalikan oleh keseimbangan energy permukaan tanah (Becker, 1990).

Teknik penginderaan jauh sebelumnya pernah dimanfaatkan dalam penelitian, seperti penelitian Togi (2016) mengenai identifikasi panas bumi dengan sistem informasi geografis dan pengindraan jarak jauh panas bumi di Kecamatan Dolok Merawa, di peroleh hasil Suhu Permukaan Tanah (LST) minimumnya adalah $2.720490^{\circ} \mathrm{C}$ dan nilai maksimum adalah $37.889587^{\circ} \mathrm{C}$. Data tersebut digunakan sebagai data masukan untuk ENVI 4.7 dan ArcGIS 10 sebagai alat penghitung suhu permukaan tanah. Maka, disimpulkan bahwa lokasi penelitian di desa Dolok Merawa itu berpotensi untuk sumber energi panas bumi dan hasil ini dapat digunakan sebagai acuan untuk eksploitasi lebih lanjut panas bumi.

\section{METODE PENLITIAN}

\section{Tempat dan Waktu Penelitian}

Secara Geografis letak Kabupaten Tapanuli Utara berada diantara $1^{\circ} 20^{\prime}-2^{\circ} 41^{\prime}$ Lintang Utara dan $98^{\circ} 05^{\prime}-99^{\circ} 16^{\prime}$ Bujur Timur yang tergolong datar (3,16 persen), landai (26,86 persen), miring (25,63 persen) dan terjal $(44,35$ persen). Penelitian ini dilaksakan pada 23 April 2018 sampai 25 April 2018.

\section{Alat dan Bahan Penelitian}

\section{Alat Penelitian}

GPS (Global Position Systems), computer dengan ArcGis 10.0ENVI 4.7, DNS GARMIN, Microsoft Office 2010, Kamera Digital, alat tulis.

\section{Bahan Penelitian:}

$\begin{array}{llll}\text { Citra Satelit Landsat } 8 & \text { OLI }\end{array}$ (http://glovis.usgs.gov), Peta Rupa Bumi Sumatera Utara

(http://www.bakosurtanal.go.id/petarupabumi/),_Peta Administrasi Kabupaten Tapanuli Utara.

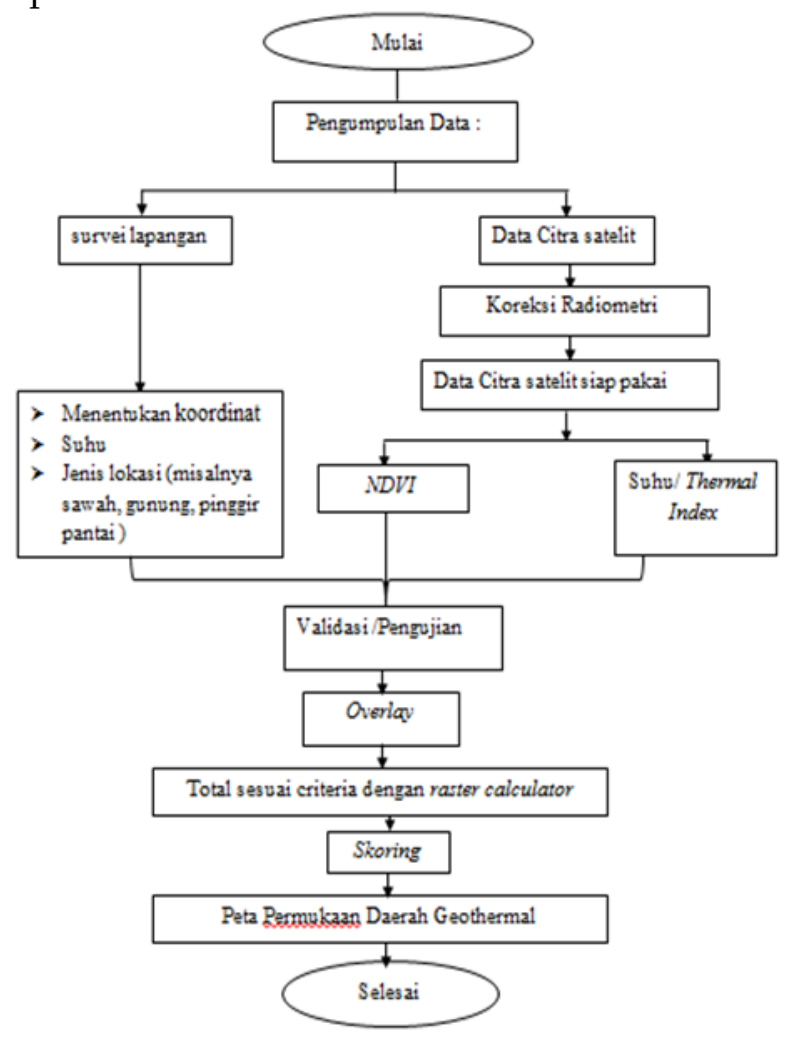

Gambar 1. Diagram Alir Pelaksanaan Penelitian

\section{HASIL DAN PEMBAHASAN}

\section{Hasil Penelitian}

a. Normalized Different Vegetation Indeks (NDVI)

NDVI didapat dengan menginput band 4 dan band 5 dari citra Landsat 8 OLI dan menggunakan persamaan NDVI kemudian lakukan ekstraksi informasi.

Rumus untuk mencari NDVI adalah sebagai berikut: 
Togi Tampubolon* dan Yowlanda Panggabean, Identifikasi Permukaan Daerah Geothermal PLTP Sarulla Unit I Menggunakan Citra Satelit Di Kecamatan Pahae Jae Kabupatan Tapanuli Utara

Dimana :

$$
\mathrm{NDVI}=\frac{N I R-R e d}{N I R+R e d}
$$

- NIR (Near Infra Red) atau gelombang infra merah dekat memiliki panjang gelombang $0,63 \mu \mathrm{m}-0.69 \mu \mathrm{m}$

- $\quad \mathrm{R}$ (Red) atau gelombang merah memiliki panjang gelombang $0.76 \mu \mathrm{m}-0.90 \mu \mathrm{m}$

Sehingga formulanya dapat dituliskan sebagai berikut :

$$
\mathrm{NDVI}=\frac{\text { Band } 5-\text { Band4 }}{\text { Band } 5+\text { Band4 }}
$$

\section{a. Normalized Different Vegetation Indeks (NDVI) PLTP Sarulla Unit I}

Hasil perhitungan NDVI pada tahun 2010, 2014, 2016, 2017 dan 2018 memberikan gambaran NDVI yang dapat dilihat pada Gambar 1a, b, c, d, dan e.

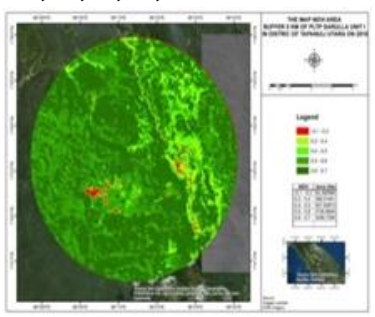

(a)

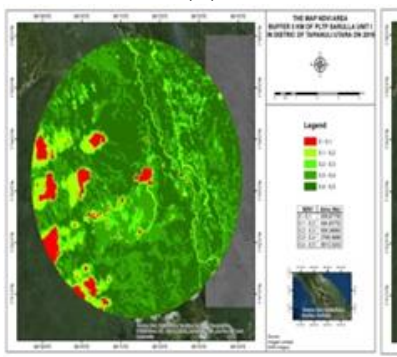

(b)

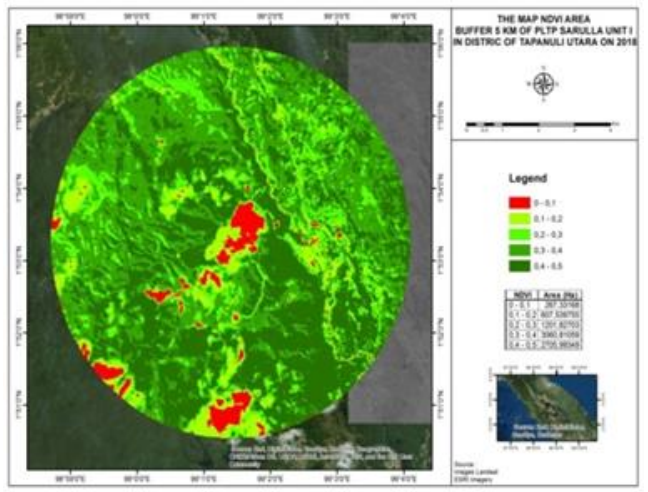

(e)

Nilai yang mewakili vegetasi berada pada rentang 0,1 hingga 0,7. Pembagian klasifikasi NDVI terbagi atas tiga bagian yaitu pada rentang $<0,2$ dikategorikan lahan terbuka, air, dan tidak bervegetasi sedangkan pada rentang 0,2 - 0,5 dikategorikan vegetasi rendah dan pada rentang $>0,5$ dikategorikan daerah vegetasi tinggi. Dapat dilihat pada gambar hasil perhitungan NDVI pada tahun 2010, 2014, 2016, 2017 dan 2018 di daerah PLTP Sarulla bahwa tiap tahun kerapatan vegetasi mengalami perubahan.

Tabel 1. Perubahan NDVI daerah PLTP Sarulla

$\begin{array}{lllll}2010 & 2014 & 2016 & 2017 & 2018\end{array}$

\begin{tabular}{llllll}
$\begin{array}{l}\text { NDVI } \\
\text { min }\end{array}$ & 0.5 & 0.3 & 0.1 & -0.1 & 0.1 \\
$\begin{array}{l}\text { NDVI } \\
\max \end{array}$ & 0.7 & 0.5 & 0.5 & 0.6 & 0.5 \\
$\begin{array}{l}\text { Rata- } \\
\text { rata }\end{array}$ & 0.6 & 0.4 & 0.3 & 0.25 & 0.3 \\
\hline
\end{tabular}

Dari data tabel 1 di atas didapatkan grafik perubahan rata - rata suhu di PLTP Sarulla dari tahun 2010, 2014, 2016, 2017 dan 2018. Gambar 2 di bawah ini menunjukkan grafik perubahan rata - rata suhu di PLTP Sarulla Unit I dari tahun 2010 sampai tahun 2018.

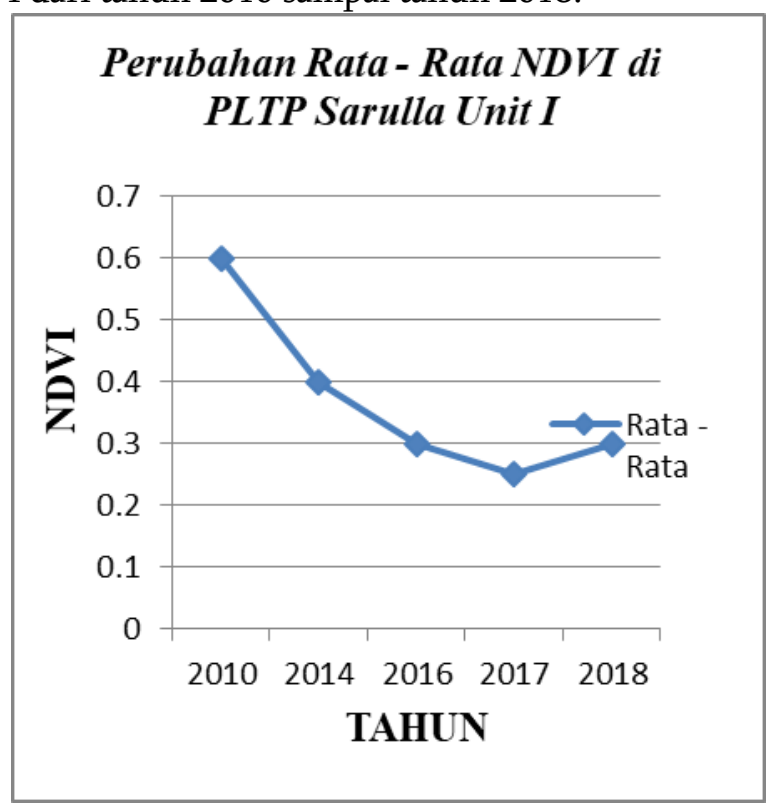

Gambar 2. Grafik Perubahan Rata - Rata NDVI di PLTP Sarulla Unit I

Dari gambar 2 di atas menunjukkan grafik keadaan perubahan rata - rata nilai NDVI di PLTP Sarulla dari tahun 2010 sampai tahun 
2018. Dimana nilai rata-rata NDVI tertinggi berada pada tahun 2010 sebesar 0.6 dan nilai rata - rata NDVI terendah berada pada tahun 2017 sebesar 0.25 .

b. Indeks Temperatur (Thermal Index, TI)

Indeks Temperatur (TI) didapat dengan memanfaatkan Band 6 (Long Wavelength InfraRed) untuk Landsat $5 \mathrm{TM}$, dan Band 10 (Long Wavelength InfraRed) pada Landsat 8 OLI. Hasil perhitungan TI memberikan gambaran berupa Peta TI pada tahun 2010, 2014, 2016, 2017 dan tahun 2018 dapat dilihat pada Gambar di bawah ini. Rumus untuk mencari TI adalah :

$$
T I(K)=\frac{K_{2}}{L_{n}\left(\frac{K_{1}}{L_{\lambda}}+1\right)}
$$

Keadaan indeks temperature pada tahun 2010, 2014, 2016, 2017 dan 2018 dapat dilihat pada gambar 2a, b, c, d dan e di bawah ini.

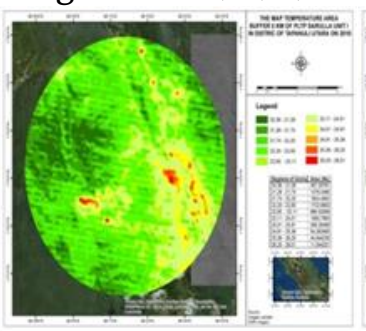

(a)

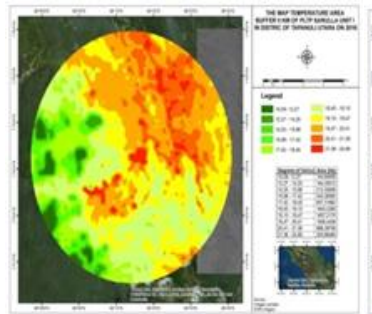

(a)

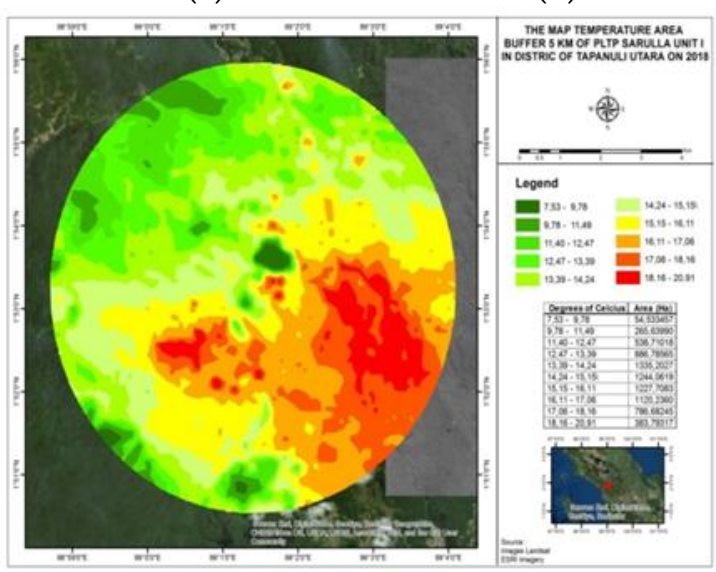

(e)

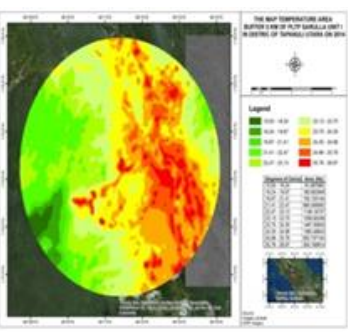

(b)

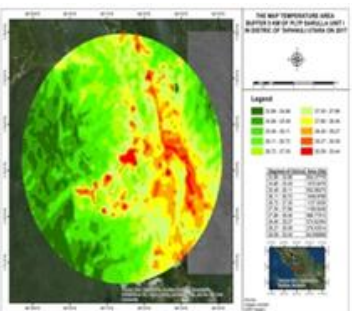

(b)
Dari gambar di atas didapatkan data Temperature Index (TI) dari tahun 2010, 2014, 2016, 2017 dan 2018 dapat dibuat rata - rata keadaan perubahan suhu yang terjadi di daerah PLTP Sarulla Unit I yang dapat dilihat pada tabel 2 di bawah ini.

Tabel 2. Perubahan Suhu Rata - Rata daerah PLTP Sarulla Unit I

\section{$\begin{array}{lllll}2010 & 2014 & 2016 & 2017 & 2018\end{array}$}

\section{TI \\ $\begin{array}{llllll}\min & 23.11 & 24.35 & 19.47 & 29.27 & 17.06\end{array}$ \\ TI \\ $\begin{array}{llllll}\max & 28.01 & 28.97 & 24.69 & 33.44 & 20.91\end{array}$}

Rata-

$\begin{array}{llllll}\text { rata } & 25.56 & 26.66 & 22.08 & 29.53 & 19.52\end{array}$

Dari data tabel 2 didapatkan grafik perubahan rata - rata suhu di PLTP Sarulla dari tahun 2010, 2014, 2016, 2017 dan 2018. Gambar 3 di bawah ini menunjukkan grafik perubahan rata - rata suhu di PLTP Sarulla Unit I dari tahun 2010 sampai tahun 2018.

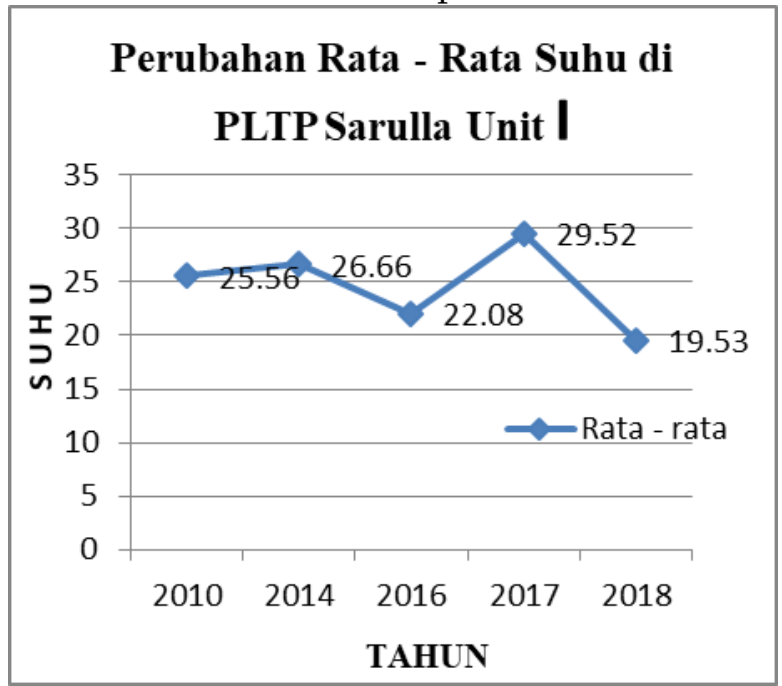

Gambar 3. Grafik Perubahan Suhu Rata - Rata di PLTP Sarulla Unit I

Berdasarkan peta indeks temperatur suhu di PLTP Sarulla Unit I suhu tertinggi digambarkan oleh warna merah dan suhu terendah digambarkan pada warna hijau. Terlihat pada tahun 2017 di sekitar PLTP Sarulla Unit I mengalami suhu tertinggi 
mencapai 31,350C dibandingkan tahun - tahun lainnya dan suhu terendah terdapat pada tahun 2018 yaitu 19,530 C yang dapat disebabkan oleh pengaruh iklim yang terjadi.

Dari data nilai NDVI dan LST yang didapatkan dari tahun 2010, 2014, 2016, 2017 dan 2018 secara rinci dapat dilihat padatabel 3 di bawah ini.

Tabel 3. Nilai NDVI dan LST pada tahun

\begin{tabular}{|c|c|c|}
\hline Tahun & NDVI & LST \\
\hline 2010 & 0,6 & 25,56 \\
\hline 2014 & 0,4 & 26,66 \\
\hline 2016 & 0,3 & 22,08 \\
\hline 2017 & 0.25 & 29,52 \\
\hline 2018 & 0.3 & 19,53 \\
\hline
\end{tabular}

Dari tabel diatas menunjukkan penurunan nilai NDVI yang berarti terjadinya penurunan tingkat kepadatan vegetasi yang menyebabkan meningkatnya suhu (LST) di Kabupaten Tapanuli Utara.

\section{KESIMPULAN DAN SARAN}

Dari hasil penelitian yang dilakukan maka dapat diambil kesimpulan antara lain.

1. Perubahan vegetasi dinilai berdasarkan indeks NDVI dari tahun 2013, 2014, 2016, 2017 dan 2018 yakni 0,6; 0,4; 0,3; 0,25 dan 0,3. Hal ini membuktikan adanya penurunan nilai NDVI yang meyatakan penurunan vegetasi. Perubahan suhu dinilai berdasarkan indeks TI dari tahun 2010 sampai dengan tahun 2018 yakni 25,56; 26,66; 22,08; 29.52 dan 19.53. Hal ini membuktikan adanya peningkatan nilai TI yang menyatakan peningkatan suhu.

2. Hubungan antara NDVI dengan LST berbanding terbalik, apabila nilai NDVI tinggi maka nilai LST rendah, seperti nilai NDVI untuk hutan $>0,6$ sementara nilai suhu di rentang 200C $-300 \mathrm{C}$, dan sebaliknya apabila nilai NDVI rendah maka nilai LST tinggi seperti daerah pemukiman yang memiliki nilai NDVI di rentang $0-0,25$ dan suhu $>300 \mathrm{C}$.

3. Parameter NDVI dan LST terhadap perubahan lingkungan sangat berpengaruh. Alih fungsi lahan merupakan salah satu jenis perubahan lingkungan yang dilihat dari segi kerapatan vegetasi. Rapat atau tidaknya vegetasi mempengaruhi suhu permukaan pada suatu lingkungan.

4. Dari semua rangkaian penelitian yang telah dilakukan, ada beberapa saran yang dapat dilakukan untuk pengembangan penelitian ini, yaitu :

5. Melakukan penambahan titik kontrol lapangan (GCP) yang diambil langsung di lokasi penelitian dan melakukan pengolahan dengan data terbaru untuk pembaharuan informasi yang berkelanjutan.

\section{DAFTAR PUSTAKA}

Becker, F., and LI, Z. L., (1990), Toward a Local Split Window Method Over Land Surface. International Journal of Remote Sensing, Vol. 11(3), hal. 369393.

Dickson, Fanelli, M., (2013), Geothermal Energy Utilization and Technology. United Kingdom. Routledge.

Howard, J. A., (1996), Penginderaan Jauh untuk Sumber Haya Hutan: Teori dan Aplikasi, Gadjah Mada University Press, Yogyakarta.

Huete, A., Justice, C., Leeuwen, W. V. 1999. Modis Vegetation Index (Mod 13) Algorithm Theoretical Basis Document. Pdf di Pulau Saparua Maluku Tengah. E-Jurnal Ilmu dan Teknologi Kelautan

Lillesand, T.M., dan F.W. Kiefer, (1979), Penginderaan Jauh dan Interpretasi Citra, Yogyakarta, Gadjah Mada University Press.

(Kementrian ESDM (AntaraNews/Istimewa), 2017).http://Www.Antaranews.Com/B erita/652019/IndonesiaDiproyeksikanSebagai-Penghasil Geothermal Terbesar-2021 
Marzolf N., (2014), Emprendimiento de la energía geotérmica en Colombia, Banco Interamericano del Desarrollo. ISAGEN..https://publications.iadb.org/ bitstream/handle/11319/6558/Energia \%20Geotermica\%20Colombia\%207-114final- web.pdf?sequence $=1$. Accessed 20 November 2017.

Muñoz Y, Guerrero J, Ospino A. Evaluation of a hybrid system of renewable electricity generation for a remote area of Colombia using homer software. Tecciencia. 2014;9(17):45-54. https://doi.org/10.18180/tecciencia.201 4.17.6.

Togi,T., Khairuddin, A., Lim. H. S., Jeddah. Y., (2016), The Identification Of Geothermal With Geographic Information System And Remote Sensing In Distric Of Dolok Merawa. Internasional Physics Symposium. Tropis. Vol.2, No.1, Hal 50-58, Juni 2010. 